\title{
Bilateral spreading depression and avoidance learning in rats'
}

GORDON WINOCUR

UNIVERSITY OF WATERLOO

\begin{abstract}
Abstraet
Bilateral spreading depression (BSD) produces a significant motor loss which contributes to impaired avoidance learning. When rats under BSD were tested on two tasks equated for difficulty but varying in motor complexity, greater impairment was found in the task requiring the more complex response. Transfer of learning from the normal to the cortically depressed state was found only in Ss tested in the less complex task.

\section{Problem}

Functional cortical ablation produced by bilateral spreading depression (BSD) invariably results in impaired avoidance learning in rats (Bures, Buresova \& Zahorva, 1958; Tapp, 1962; Travis \& Sparks, 1963; Bures, 1959). Bures has attributed this loss to a disturbance of cortical mechanisms involved in the learning process. Tapp (1962), on the other hand, reported a significant correlation between the loss of a conditioned avoidance habit and impaired sensorimotor co-ordination due to BSD. Tapp's evidence implies that stimulus and response complexity are important variables which may affect the performance of BSD animals in avoidance situations. A recent study by Thompson \& Hjelle (1965) has indeed shown this to be so. Thompson and Hjelle's data, however, are confounded by the fact that an increase in response complexity is accompanied by a corresponding increase in task difficulty as demonstrated in his controls. The present experiment separated the motor and learning effects of BSD by testing rats on two tasks (Tasks A and B) proven to be of equal difficulty for normal animals but differing in motor complexity.

A second problem examined in this experiment was that of transfer of learning from the normal to the BSD state. Studies which have investigated this effect have produced inconclusive results. Tapp (1962) found that a conditioned avoidance response learned with the cortex normal did not transfer to the BSD state. On the other hand, Thompson (1964) found that rats pretrained on an avoidance problem with a functional cortex did show positive transfer when later tested under BSD. A comparison was therefore made between BSD with prior training and BSD without prior training.

Method

Ss were divided into two main groups-BSD $(N=40)$ and Sham $(\mathrm{N}=40)$. Both major groups consisted of a Task A group $(\mathrm{N}=20)$ and a Task $B$ group $(\mathrm{N}=20)$. Within each task, Ss were further subdivided into Pretraining $(\mathrm{N}=10)$ and no Pre-training $(\mathrm{N}=10)$ conditions.
Pre-training took place immediately prior to operation and consisted of avoidance learning to a criterion of $9 / 10$ correct responses. After operation which involved bilateral exposure of the parietal cortex with a $4 \mathrm{~mm}$ trephine opening, $\mathrm{S}$ was returned to the home cage. Following a $24 \mathrm{hr}$. recovery period, BSD was produced according to the technique of Bures, Buresova, \& Zahorva (1958). S was lightly anesthetized under ether and the wound reopened. A $4 \mathrm{~mm}$ circle of filter paper either soaked in $25 \% \mathrm{KCl}$ (BSD Ss) or untreated (Sham Ss) was applied directly to the exposed dura of both hemispheres. The incision was then closed with wound clips. Twenty to $30 \mathrm{~min}$. later, all Ss received one 30 -trial test session under uniform testing procedures. On each trial, Ss were allowed $5 \mathrm{sec}$. in which to run from the start box to the safe compartment to avoid shock.

The testing apparatus (a modified Yerkes-Thompson discrimination box) consisted of a wooden chamber (40 in long) divided into a start box (7-1/2 in long), a runway (21 in long), and a safe goal compartment (11-1/2 in long). A manually controlled sliding door separated the start box from the runway. In Task A, the safe compartment was entered through one of two open doorways ( 6 in wide) separated by a $1 / 4$ in thick center post extending the height of the box. In Task $B$, both doors were closed except for a small window (2-1/4 in $x 3$ in) located centrally about 2-1/2 in from the floor. Ss were required to find the window and climb through it to avoid shock.

\section{Results and Diseussion}

Preliminary investigation revealed that normal animals showed equal learning ability on both tasks. This was confirmed in the experiment by the pretrained Ss who made an equal number of errors and required the same number of trials to learn either task to criterion (Table 1).

As expected, BSD Ss showed a marked impairment in avoidance learning. Under all conditions, BSD Ss failed to avoid more often than Sham groups $(p<.01)$. A

\section{TABLE I}

MEAN NUMBER OF TRIALS REQUIRED AND ERRORS MADE BY NORMAL ANIMALS IN REACHING A CRITERION OF 9/10 CORRECT RESPONSES ON TASKS A AND B

\begin{tabular}{lcc} 
& $\begin{array}{c}\text { Task } A \\
(\mathrm{~N}=20)\end{array}$ & $\begin{array}{c}\text { Task B } \\
(\mathrm{N}=20)\end{array}$ \\
\hline Trials to Criterion & 13.9 & 14.2 \\
\hline Errors to Criterion & 4.6 & 4.7 \\
\hline
\end{tabular}


TABLE 2

MEDIAN NUMBER OF ERRORS MADE BY BSD AND SHAM

GROUPS ON 30 TRIAL TESTING SESSION FOLLOWING CONDITIONS OF PRE-OPERATIVE AND NO PRE-OPERATIVE TRAINING

\begin{tabular}{cccc} 
& & \multicolumn{2}{c}{ Errors in 30 Trials } \\
\hline \multirow{2}{*}{ BSD } & Task A & Task B \\
\cline { 2 - 4 } & Pre-training & 12.5 & 30.0 \\
\cline { 2 - 4 } & No Pre-training & 18.0 & 30.0 \\
\hline \multirow{2}{*}{ Sham } & Pre-training & 6.5 & 9.5 \\
\cline { 2 - 4 } & No Pre-training & 9.0 & 11.0 \\
\hline
\end{tabular}

major finding was that BSD Ss were more impaired on Task B than on Task A. Median differences between Task A and Task B conditions were obtained for each of the four groups (Table 2). A chi-square analysis revealed that the difference between the tasks was significantly greater for the BSD than for the Sham Ss $(p<.01)$ both for the pretrained and untrained Ss. As a further control for the effects of operational procedure, a third group made up of normal Ss was run on Task A with no prior training. When the scores of this group were compared with those of their corresponding Sham group, a significant difference was found $(p<.01)$, suggesting that at least to a limited degree, Shams were being affected by surgical treatment.

Both Sham groups receiving pre-training showed positive savings when tested. The BSD Ss tested on Task A also showed this effect $(p<.02)$. It is not possible to make a definite statement regarding transfer in the Task B-BSD group. Ss in this group appeared unable to make the appropriate response, therefore any transfer of learning may have been masked by their inability to master the motor requirements of the problem. Thus there is evidence for transfer of training from the normal to cortically depressed state at least in the task which involved less motor complexity.

The data in this experiment confirm the finding that Ss under BSD suffer a loss of motor co-ordination (Tapp, 1961) and are most impaired on those tasks which require a relatively high level of response complexity (Thompson \& Hjelle, 1965). This effect was shown to be independent of task difficulty as defined by speed of learning in normals, a factor which had not previously been controlled. The evidence also supports an earlier finding (Thompson, 1964) that transfer of learning may occur from the normal to SD state and suggests that failure to demonstate such transfer (Tapp, 1962) may be related to response complexity of the task.

\section{References}

Bures, J. Reversible decortication and behavior. In M. A. Brazier (Ed.), Conference on the nervous system and behavior. New York: Josiah Macey, Jr. Foundation, 1959. Pp. 207-248.

Bures, J., Buresova, o., \& Zahorva, A. Conditioned reflexes and Leao's spreading cortical depression. J. comp. physiol. Psychol., 1958, 51, 263-268.

Tapp, J. T. Reversible cortical depression and avoidance behavior in the rat. J. comp. physiol. Psychol., 1962, 55, 306-308.

Travis, R. P., \& Sparks, D. L. The influence of unilateral and bilateral spreading depression during learning upon subsequent relearning. J. comp. physiol. Psychol., 1963, 56, 56-59.

Thompson, R. W. Transfer of avoidance learning between normal and functionally decorticate states. J. comp. physiol. Psychol., 1964, 57, 321-325.

Thompson, R. W., \& Hjelle, L. A. Effects of stimulus and response complexity on learning under bilateral spreading depression. J. comp. physiol. Psychol., 1965, 59, 122-124.

\section{Note}

1. This study was carried out at the University of Manitoba and supported in part by the National Research Council, grant No. NR-APA-76, held by Dr. R. M. Cooper and by the Medical Research Council at the University of Manitoba, grant No. MA-1220 held by Dr. K. R. Hughes. Their assistance and that of Drs. E. A. Salzen and G. V. Goddard, University of Waterloo, is gratefully acknowledged. 